\title{
Transição para a parentalidade e a coparentalidade: casais que os filhos ingressaram na escola ao término da licença-maternidade
}

\author{
The Transition to Parenting and Coparenting: Couples that Children were Enrolled \\ in School on the Espiration of Maternity Leave
}

\section{Transición a la parentalidad y coparentalidad: parejas cuyos hijos ingresaron a la escuela al finalizar la licencia de maternidad}

\author{
Liana Pasinato, ${ }^{*}$ Clarisse Pereira Mosmann* \\ Universidade do Vale do Rio dos Sinos (Unisinos), Brasil.
}

Doi: dx.doi.org/10.12804/ap134.1.2016.09

\section{Resumo}

O presente estudo investigou a transição para a parentalidade e a coparentalidade em casais que os filhos ingressaram na escola de educação infantil logo após o término da licença-maternidade. Foi realizado um estudo de delineamento exploratório e descritivo, com método de análise dos dados qualitativo, por meio da análise de conteúdo. Quatro casais/pais de duplo trabalho, com idades entre 26 e 40 anos responderam a um questionário de dados sociodemográficos e uma entrevista semiestruturada sobre coparentalidade. Os resultados indicaram que, durante a transição para a parentalidade, os genitores preservam mais seus espaços pessoais, enquanto as genitoras se sentem sobrecarregadas por se responsabilizarem por todas as demandas que envolvem esse período. Já a coparentalidade é desempenhada de forma mais igualitária, uma vez que a inserção esco- lar precoce dos filhos e o duplo trabalho impõem essa dinâmica. Em contrapartida, as tarefas domésticas ainda não são divididas igualitariamente, estando estas associadas aos papéis de gênero. Os resultados permitiram uma aproximação com a realidade desses casais, que apontou indícios de mudanças no desempenho de sua coparentalidade.

Palavras chave: dupla carreira; escolas maternais; relações familiares.

\section{Abstract}

This study investigates the transition to parenthood and coparenting in couples whose children entered nursery school right after the end of maternity leave. A descriptive and exploratory study was carried out with a qualitative data analysis method, through content analysis. Four double-working couples/parents aged

* Liana Pasinato, mestre em Psicologia Clínica pela Universidade do Vale do Rio dos Sinos, Brasil; Clarisse Pereira Mosmann, professora do Programa de Pós-Graduação e do Curso de Psicologia da Universidade do Vale do Rio dos Sinos, Brasil.

A correspondência relacionada com este artigo deve se dirigir a Liana Pasinato. Correio eletrônico: lia.pasinato@yahoo.com.br

Como citar este artigo: Pasinato, L. \& Mosmann, C. (2016). Transição para a parentalidade e a coparentalidade: casais que os filhos ingressaram na escola ao término da licença-maternidade. Avances en Psicología Latinoamericana, 34(1), 129-142. doi: dx.doi.org/10.12804/apl34.1.2016.09 
from 26 to 40 years-old answered a sociodemographic data questionnaire and a semi-structured interview about coparenting. The results indicate that during the transition to parenthood, the fathers preserve better their personal spaces, while mothers feel overwhelmed, as they assume all demands involving this period. On the other hand, coparenting is performed more equally, since the double-work and consequently, early school insertion of the children impose this dynamic. In contrast, household chores are not shared equally, being these associated with gender roles. The results allowed an approach to the reality of these couples, which pointed out evidence of changes in their performance of coparenting.

Key words: dual career; nursing schools; family relations.

\section{Resumen}

El presente estudio investigó la transición a la parentalidad y coparentalidad en parejas cuyos hijos entraron a la educación infantil de la escuela, inmediatamente después de la finalización de la licencia de maternidad. Se realizó un estudio de diseño exploratorio y descriptivo, con análisis de datos cualitativos, por medio del análisis de contenido. A cuatro parejas/padres con doble trabajo y edades entre 26 y 40 años, se les aplicó un cuestionario sociodemográfico y se les realizó una entrevista semiestructurada sobre coparentalidad. Los resultados indicaron que, durante la transición a la parentalidad, los padres conservan sus espacios más personales; mientras que las madres se sienten sobrecargadas al responsabilizarse por todas las demandas que implican este periodo. Ya la coparentalidad se lleva a cabo de manera más equitativa, por la inclusión temprana de los niños a la escuela y el doble trabajo que esta dinámica les impone. Por el contrario, las tareas domésticas no se dividen por igual, ya que están asociadas a los roles de género. Los resultados permitieron una aproximación a la realidad de estas parejas, que mostraron indicios de cambio en el desempeño de su coparentalidad.

Palabras clave: carreras dobles; escuelas maternas; relaciones familiares.
A transição para a parentalidade configura-se como uma etapa de crise do sistema familiar, caracterizada por mudanças impactantes sobre a vida e sobre o relacionamento dos indivíduos que a experimentam. Durante esse período, novos papéis precisam ser aprendidos, novos relacionamentos desenvolvidos e os já existentes necessitam ser reordenados (Hernandez \& Hutz, 2009).

Atualmente, devido às características de duplo trabalho dos pais, as crianças estão ingressando na escola logo após o término da licença-maternidade. Isso gera uma sobreposição de duas etapas do ciclo de vida da família, que, antigamente, eram marcadamente distintas, culminando em uma maior complexidade. Existia uma diferença no momento de transição da conjugalidade para a parentalidade e a coparentalidade, com tarefas e demandas específicas. Anteriormente, as avós e tias as que habitavam junto à família participavam da guarda e da educação das crianças, facilitando para que ocorresse, posteriormente, a entrada dos filhos na escola. Hoje, sabe-se que elas estão incorporadas também à população ativa (Gravena, 2006; Rizzo, 2010).

Uma etapa de crise evolutiva vital das famílias foi antecipada cronologicamente, já que dificilmente podem contar com rede de apoio social (Seabra, 2007), entendida aqui como as inter-relações que estabelecem com amigos, familiares e a comunidade em geral, as quais, através do suporte mútuo, sustentam o sentimento de bem-estar psicossocial (Sluzki, 1996). Com o duplo trabalho e não havendo familiares disponíveis, os casais precisam inserir as crianças na escola, a qual possui horário e rotina especifica, que precisam ser coordenadas com os horários dos trabalhos de cada genitor, e mais as tarefas domésticas e de cuidados com a criança.

Nesse contexto, em famílias nucleares, durante a transição da conjugalidade para a parentalidade, os pais necessitam assumir um papel diferente do desempenhado até então, pois o sentimento de maternidade e de paternidade é carregado de emotividade, o que às vezes resulta difícil de ser viven- 
ciado. O surgimento das novas funções vem com o envolvimento dos pais com os filhos que necessitam de cuidados e de afeto, estabelecendo uma relação de dependência com seus genitores durante boa parte do tempo. As dificuldades surgem na medida em que tanto o pai quanto a mãe precisam dar seu amor ao novo filho, continuando a fazer o mesmo com seu respectivo cônjuge. Dessa forma, nesse período, ocorrem modificações na estrutura, nos papéis e nas funções, e essa transição pressupõe certos níveis de flexibilidade para que o sistema consiga-se adaptar e atingir uma nova dinâmica familiar (Ríos-González, 2005).

No contexto nacional, Menezes e Lopes (2007) buscaram analisar a relação conjugal durante a transição para a parentalidade sob dois enfoques: a avaliação que cada casal fez de sua relação e a interação comunicacional estabelecida nos diferentes momentos de transição. Os pesquisadores realizaram um estudo de caso coletivo e longitudinal que abrangeu cinco etapas: o último trimestre da gestação e o terceiro, o oitavo, o décimo-segundo e o décimo oitavo meses de vida dos bebês.

A amostra foi composta por quatro casais adultos, com idades entre 20 e 30 anos, que esperavam seu primeiro filho e que foram recrutados em grupos de preparação para gestantes em hospitais de Porto Alegre. Os resultados indicaram que a parentalidade pode-se manifestar de diferentes formas em cada casal. Entretanto, a participação, ou não, dos homens na função parental mostrou-se relacionada à qualidade da conjugalidade. De acordo com os autores, durante a transição para a parentalidade, os casais que apresentavam uma relação de envolvimento emocional puderam aprimorá-la e manifestar isso por meio do aumento da emissão de respostas apoiadoras ao cônjuge. Enquanto isso, os casais que já tinham um distanciamento afetivo sentiram mais o impacto dessa transição, diminuindo a forma apoiadora de interagir com o cônjuge.

No momento em que se estabelece o subsistema parental, instaura-se também o subsistema coparental. Esse último é definido pelo envolvimento conjunto e recíproco de ambos os pais na educação, na formação e nas decisões sobre a vida de seus filhos (Feinberg, 2003). Para definição do termo coparentalidade, é necessária a presença de duas (Grzybowski \& Wagner, 2010), ou mais pessoas envolvidas e responsáveis pela educação dos filhos (McHale, Kuersten-Hogan \& Rao, 2004). Apenas se excluem da relação coparental os aspectos legais, românticos, sexuais, emocionais e/ou financeiros dos relacionamentos adultos que não têm relação com os cuidados sobre a criança (Feinberg, 2003).

As pesquisas que analisam as associações ao desenvolvimento infantil enfocam a importância de bons níveis de acordo coparental e baixos índices de conflito e de competição coparental (Mosmann, Einsfeld, Silva \& Terres-Trindade, 2012; Lamela, Costa, \& Figueiredo, 2010). Por acordo coparental entende-se a afirmação da competência do outro genitor como pai/mãe, reconhecendo e respeitando suas contribuições e sustentando suas decisões. Em contrapartida, alguns genitores adotam uma postura competitiva, minando um ao outro com a crítica, o menosprezo e a culpa. Ou seja, o ganho de um dos genitores em relação à autoridade e/ ou ao afeto com relação aos filhos pode ser compreendido como uma perda para o outro. Portanto, o comportamento dos filhos é afetado não somente pela relação pais-filhos, mas também pela coparentalidade, quando os cônjuges falham no suporte um ao outro e expressam aos filhos práticas educativas contraditórias.

Muitas variáveis podem-se expressar na forma como o casal vai estabelecer sua relação coparental. Além dos aspectos dinâmicos do casal, existem elementos contextuais que podem-se refletir nesse momento. Em função de tradicionais diferenças de gênero presentes em nossa cultura, percebe-se que, ao mesmo tempo em que o pai deseja participar da vida do bebê, ele pode-se perceber como excluído, uma vez que o cuidado dos filhos ainda é assumido socialmente como uma habilidade natural feminina (Badinter, 2011; Bornholdt, Wagner $\&$ Staudt, 2007) e muitas mulheres não permitem 
uma maior participação dos homens. Ou seja, os casais que procuram dividir os cuidados do filho e os deveres de provedor em bases iguais necessitam negociar seus papéis num contexto social, onde a regra que tem sido aceita é a de que a mãe seja a encarregada pelo cuidado do filho e o pai ajuda-a. Essa crença tem sido reforçada também pela disponibilidade criada pela licença-maternidade, e pelo tempo exíguo da licença-paternidade (Cooper \& Lewis, 2000), uma vez que a legislação brasileira prevê cento e vinte dias de licença para as mães e cinco dias para os pais. Nesse contexto, é reforçada a concepção tradicional de família, composta de um homem provedor e uma mulher dedicada aos cuidados do lar (Pinheiro, Galiza \& Fontoura, 2009). Ou seja, não existe incentivo por parte do estado para um maior envolvimento dos genitores com seus filhos.

Em contrapartida, na Suécia, desde 1974, a licença-maternidade tornou-se um benefício remunerado para ambos os pais, com o objetivo de estimular os homens a assumirem um papel mais ativo na criação dos filhos e de propiciar uma divisão mais igualitária das tarefas domésticas. De acordo com a legislação sueca, até o terceiro mês a licença é para o pai e para a mãe e, depois disso, o casal opta sobre qual dos dois continuará de licença parental, podendo esse período ser alternado para que tanto o pai quanto a mãe possam-se revezar na licença-maternidade/paternidade (Pinheiro et al., 2009).

Ao investigar o envolvimento paterno no contexto brasileiro, Beltrame e Bottoli (2010) realizaram entrevistas semiestruturadas, com quatro casais, aplicadas individualmente, a partir de fotos tiradas pelos próprios pais, que registraram o dia a dia da família. Nesse estudo, observou-se que ser pai, na atualidade, na visão da mulher e do homem, afasta-se e aproxima-se dos modelos tradicionais, ou seja, os pais encontram-se num momento de transição, exercendo antigos e novos papéis. É exigida uma nova postura dos homens, em que novas funções e papéis são esperados não somente por ingressarem em uma nova etapa do ciclo vital, mas também porque a sociedade e a mídia cobram um pai mais envolvido no cuidado com os filhos (Freitas, Silva, Coelho, Guedes \& Costa, 2009; Staudt \& Wagner, 2008).

Porém, quando, por necessidade, os pais oferecem cuidados como dar banho, dar comida, trocar fralda, dentre outros, aparece a ideia de que o homem estaria ajudando ou auxiliando a mulher (Bustamante \& Trad, 2005). Cabe ressaltar que o envolvimento paterno no cuidado dos filhos não significa uma apropriação da vida doméstica em si, pois ainda permanece a distinção entre ser pai e ser dono de casa, sendo a última ainda vivida com muito estranhamento (Sutter \& Bucher-Maluschke, 2008).

Também, com objetivo de investigar as experiências e os sentimentos de pais em relação à própria paternidade, Gabriel e Dias (2011) realizaram um estudo qualitativo, através da análise de conteúdo (Bardin, 1977). Participaram oito homens, pais primíparos, com idades entre 28 e 41 anos, que responderam a uma entrevista semiestruturada. Os resultados revelaram que, mesmo os pais colocando-se como envolvidos, essa participação refere-se ao tempo em que estão disponíveis e não à sua integralidade. A mãe e/ou a escola ainda são as principais responsáveis pela criança durante o dia. Portanto, essa falta de consistência, segundo os autores, entre o discurso e o fazer paterno, faz parte do momento sócio histórico que o homem tem vivenciado um período de transição na constituição de seu papel.

Nesse sentido, a literatura sugere que existe uma coexistência de modelos familiares, não havendo predominância de um tipo de estrutura. Em algumas famílias, persiste a tradicional divisão de papéis; em outras, marido e esposa dividem as tarefas domésticas e educativas, e identificam-se, ainda, as famílias em que a mulher é a principal provedora do sustento econômico familiar (Wagner, Predebon, Mosmann \& Verza, 2005; Fleck \& Wagner, 2003). É consensual que, ao ingressar a 
mulher ao mercado de trabalho, os homens foram impelidos a dividir com a esposa os trabalhos domésticos e a criação dos filhos. Segundo Gomes e Resende (2004) a dinâmica familiar muda nos casais de duplo trabalho, pois não há como o homem não participar da vida familiar, devido à falta de tempo das mulheres.

Assim, alguns estudos têm-se dedicado a analisar a divisão de papéis e de funções de pais e de mães no contexto de duplo trabalho. Souza, Wagner, Branco e Reichert (2007) realizaram um estudo de casos múltiplos (Yin, 1993) com quatro famílias, utilizando para coleta de dados a entrevista familiar estruturada (Féres-Carneiro, 1996), e um questionário que investigou dados biodemográficos e aspectos do funcionamento e da estrutura dessas famílias. Os resultados apontaram que as mulheres ainda são responsabilizadas pelo bem-estar das famílias e principalmente pelo trabalho doméstico. A contribuição dos homens aparece de forma mais intensa no cuidado e no acompanhamento do desenvolvimento dos filhos e em atividades de lazer e de culinária nos finais de semana.

Já Seabra e Seidl-de-Moura (2011) investigaram os aspectos do envolvimento paterno, tendo como base teórica a abordagem sociocultural. Participaram dessa pesquisa sete famílias quando seus filhos primogênitos estavam com 5, 20 e 36 meses. As mães responderam o instrumento Estilo Paterno e foi realizada uma entrevista com os pais para investigar o nível de satisfação paterno e materno com o envolvimento do pai com os filhos e identificando em que aspectos essa participação é mais ou menos frequente. Os resultados encontrados afastam esse grupo de pais das características da paternidade tradicional. Percebe-se uma tendência de envolvimento do pai no cotidiano dos filhos, tanto nos aspectos de lazer como nos de cuidado, e um aumento dessa participação juntamente com o aumento da idade dos filhos.

Questiona-se, então, como se configura esse fenômeno da transição para a parentalidade e para a coparentalidade, somado ao ingresso precoce dos filhos na escola de educação infantil. Neste estudo, considera-se ingresso precoce a entrada dos bebês na escola de educação infantil logo após o término da licença-maternidade. Nesse sentido, cabe destacar que as escolas de educação infantil tornaram-se mais importantes com a entrada das mulheres no mercado de trabalho, a partir da Revolução Industrial, ao colaborar para que as mães participassem do processo produtivo e tivessem onde deixar seus filhos.

Anteriormente, essas escolas ocupavam-se apenas com os cuidados básicos para sobrevivência das crianças. Atualmente, ampliou-se essa concepção, pois as escolas de educação infantil favorecem o desenvolvimento das crianças nos seus diversos aspectos: cognitivo, psicomotor, afetivo e psicossocial (Araújo, Gama \& Silva, 2013). São, atualmente, para grande parte das famílias, a única alternativa para as mães, que necessitam regressar ao trabalho logo após o término da licença-maternidade, gerando uma expressiva demanda de articulação entre os genitores para dar conta dos cuidados com o filho, das demandas da escola e de seus trabalhos.

Vanalli e Barham (2012) entrevistaram 40 professoras de escolas públicas do interior paulista, mães de filhos de até dois anos. $\mathrm{O}$ intuito foi o de investigar as vivências delas depois do retorno da licença-maternidade, examinando a divisão de tarefas com seus cônjuges, a satisfação com seu envolvimento familiar e o do cônjuge e com sua rede social de apoio. A maioria das mães relatou dedicar-se o dobro do tempo que seus cônjuges às atividades domésticas e ao cuidado dos filhos. Elas assumiam tarefas de alta frequência e com horários fixos, avaliando positivamente o envolvimento familiar do esposo, mas sistematicamente menor que os seus. Essas participantes relatavam enfrentar grande sobrecarga, apontando para a necessidade de rever a divisão do trabalho familiar.

Nesse contexto, o objetivo do presente estudo foi o de analisar as vivências da transição para parentalidade e para a coparentalidade em casais que 
os filhos ingressaram na escola de educação infantil logo depois do término da licença-maternidade.

\section{Método}

\section{Delineamento}

Foi realizado um estudo de delineamento exploratório e descritivo, com método de análise de dados qualitativo por meio da análise de conteúdo (Bardin, 1977).

O estudo exploratório tem por finalidade desenvolver, esclarecer e modificar conceitos e ideias, proporcionando uma visão geral acerca de determinado fato, sendo complementado pelo estudo descritivo, que visa a identificar as características do fenômeno (Gil, 1999). Através da análise de dados qualitativos, pode-se aprofundar a compreensão dos componentes identificados, analisando o significado que os indivíduos e/ou grupos atribuem a um problema social ou humano (Creswel, 2010). Desse modo, justifica-se a referida escolha metodológica por avaliar-se que ela pode proporcionar uma aproximação ao processo de transição da parentalidade para a coparentalidade e suas associações com as relações familiares, especificamente, com o ingresso dos filhos na escola logo depois do término da licença-maternidade.

\section{Participantes}

Participaram deste estudo quatro casais de duplo trabalho, com idades entre 26 e 40 anos, com filhos que ingressaram na escola de educação infantil logo depois do término da licença-maternidade. Todos os cônjuges possuem vínculo empregatício, com jornada de trabalho a partir de 30 horas semanais, em sua maior parte com graduação completa. No que se refere à situação conjugal, três dos quatro casais vivem em união estável, dos quais dois em segunda união. Com relação à rede social de apoio, dois casais contavam com a ajuda dos avós e dois não tinham essa possibilidade. Apenas um casal referiu contar com auxílio de uma diarista para as tarefas domésticas. Os outros três casais se organizavam entre si. O período de licença-maternidade das genitoras correspondeu aos quatro meses, conforme à tabela 1 .

Os critérios de inclusão foram: família nuclear, casais de duplo trabalho com filhos que tivessem ingressado na escola de educação infantil logo em seguida ao término da licença-maternidade (tabela 1). Devido à dificuldade para encontrar famílias que se dispusessem a participar da pesquisa, realizamos esse contato através das escolas de educação infantil, as quais forneceram contatos de casais que preenchiam os critérios de inclusão. Os casais que aceitaram participar do estudo eram heterossexuais e formavam famílias nucleares.

\section{Procedimentos de coleta de dados}

A coleta de dados foi realizada a partir de contato com Escolas Particulares do Município de Erechim/RS, as quais indicaram as famílias cujos filhos ingressaram na escola logo após o término da licença-maternidade. A pesquisadora contatou essas famílias e as convidou a participarem da pesquisa. Uma vez aceito o convite, foi agendada uma entrevista no local de maior conveniência da família, em sua residência ou no consultório da pesquisadora.

Primeiramente, foi realizada uma entrevista com os dois genitores e, ao final desta, foi agendado um novo encontro individualmente com cada genitor, quando foi repetida a mesma entrevista. Justifica-se a escolha desse segundo momento individual visando a oportunizar que os cônjuges, separadamente, se sentissem mais à vontade para avaliar as dificuldades associadas à parentalidade e à coparentalidade.

\section{Instrumentos}

Ficha de dados sociodemográficos: buscou levantar dados sobre os genitores e também sobre as 
Tabela 1

Caracterização das famílias

\begin{tabular}{|c|c|c|c|c|c|c|c|c|}
\hline \multirow{3}{*}{ Idade } & \multicolumn{2}{|l|}{ Casal A } & \multicolumn{2}{|l|}{ Casal B } & \multicolumn{2}{|l|}{ Casal C } & \multicolumn{2}{|l|}{ Casal D } \\
\hline & Mãe & Pai & Mãe & Pai & Mãe & Pai & Mãe & Pai \\
\hline & 37 & 28 & 33 & 40 & 31 & 26 & 26 & 34 \\
\hline Profissão & Pedagoga & $\begin{array}{l}\text { Gestor } \\
\text { industrial }\end{array}$ & Professora & $\begin{array}{l}\text { Policial } \\
\text { militar }\end{array}$ & - & - & Vendedora & Torneiro \\
\hline Ocupação atual & $\begin{array}{l}\text { Auxiliar } \\
\text { adminis- } \\
\text { trativa }\end{array}$ & Bancário & $\begin{array}{l}\text { Professo- } \\
\text { ra de Ed. } \\
\text { Infantil }\end{array}$ & $\begin{array}{l}\text { Capitão da } \\
\text { Brigada } \\
\text { Militar }\end{array}$ & Balconista & $\begin{array}{l}\text { Auxiliar de } \\
\text { produção }\end{array}$ & $\begin{array}{l}\text { Vendas } \\
\text { material de } \\
\text { construção }\end{array}$ & Torneiro \\
\hline $\begin{array}{l}\text { Jornada de trabalho } \\
\text { (horas) }\end{array}$ & 44 & 30 & 40 & 40 & 44 & 40 & 44 & 40 \\
\hline Escolaridade & $\begin{array}{l}\text { Graduação } \\
\text { completa }\end{array}$ & $\begin{array}{l}\text { Graduação } \\
\text { completa }\end{array}$ & $\begin{array}{l}\text { Pós-Gra- } \\
\text { duação } \\
\text { completa }\end{array}$ & $\begin{array}{l}\text { Graduação } \\
\text { completa }\end{array}$ & $\begin{array}{l}\text { Ensino } \\
\text { médio } \\
\text { completo }\end{array}$ & $\begin{array}{l}\text { Ensino } \\
\text { médio } \\
\text { completo }\end{array}$ & $\begin{array}{l}\text { Graduação } \\
\text { incompleta }\end{array}$ & $\begin{array}{l}\text { Graduação } \\
\text { completa }\end{array}$ \\
\hline $1^{\mathrm{a}} / 2^{\mathrm{a}}$ União & $1^{\mathrm{a}}$ união & $1^{\mathrm{a}}$ união & $1^{\mathrm{a}}$ união & $2^{\mathrm{a}}$ união & $1^{\mathrm{a}}$ união & $1^{\mathrm{a}}$ união & $2^{\mathrm{a}}$ união & $2^{\mathrm{a}}$ união \\
\hline Situação conjugal & \multicolumn{2}{|c|}{ União estável } & \multicolumn{2}{|l|}{ Casados } & \multicolumn{2}{|c|}{ União estável } & \multicolumn{2}{|c|}{ União estável } \\
\hline Número de filhos & \multicolumn{2}{|l|}{1} & \multicolumn{2}{|l|}{2} & \multicolumn{2}{|l|}{1} & \multicolumn{2}{|l|}{1} \\
\hline Idade dos filhos & \multicolumn{2}{|l|}{8 meses } & \multicolumn{2}{|c|}{$\begin{array}{l}\text { Filha: } 4 \text { anos e } 8 \text { meses/ } \\
\text { filho } 8 \text { meses }\end{array}$} & \multicolumn{2}{|l|}{7 meses } & \multicolumn{2}{|l|}{8 meses } \\
\hline $\begin{array}{l}\text { Idade de ingresso } \\
\text { do filho na escola }\end{array}$ & \multicolumn{2}{|l|}{4 meses } & \multicolumn{2}{|l|}{6 meses } & \multicolumn{2}{|l|}{5 meses } & \multicolumn{2}{|l|}{3 meses } \\
\hline Turno & \multicolumn{2}{|l|}{ Integral } & \multicolumn{2}{|l|}{ Integral } & \multicolumn{2}{|l|}{ Integral } & \multicolumn{2}{|l|}{ Integral } \\
\hline
\end{tabular}

Fonte: elaboração própria.

crianças: idade, renda, carga horária de trabalho e idade da criança ao ingressar na escola de educação infantil.

Entrevista sobre coparentalidade: roteiro desenvolvido pelo Núcleo de Estudos e Pesquisas em Transtorno do Desenvolvimento-UFRGS (Núcleo de Estudos e Pesquisas em Transtorno do Desenvolvimento, 2006). A entrevista foi adaptada aos objetivos do presente estudo enfocando o contexto de duplo trabalho e a inserção dos filhos à escola logo após o término da licença-maternidade. Esta se constituiu de 18 perguntas, em oito dimensões: pergunta introdutória; parentalidade; relacionamento com o filho(a); apoio mútuo; compartilhamento de cuidados; práticas educativas/valores/ expectativas; engajamento em atividades com o filho(a); engajamento em atividades com a família.

\section{Procedimentos de análise dos dados}

Todas as entrevistas foram gravadas e posteriormente transcritas e analisadas por meio do método da análise de conteúdo (Bardin, 1977). Os resultados foram compreendidos a partir da Teoria Sistêmica (Wagner, 2011).

Os resultados serão apresentados a partir de categorias e subcategorias elaboradas por meio da análise de conteúdo das entrevistas realizadas com os genitores. Cada categoria foi discutida teoricamente, diferenciando suas subcategorias, com a utilização de falas dos participantes, exemplificando o tema específico de cada uma delas.

A análise de conteúdo foi do tipo mista (Bardin, 1977), sendo as categorias e subcategorias definidas a priori: coparentalidade, apoio mútuo 
e compartilhamento de cuidados com os filhos. E as que emergiram a posteriori, mediante análise de conteúdo: transição e adaptação à parentalidade e à coparentalidade, e divisão de tarefas domésticas.

\section{Procedimentos éticos}

O trabalho atendeu às exigências éticas contempladas na resolução para pesquisas com seres humanos, segundo a Resolução 466/12 do Conselho Nacional de Saúde e do Conselho Federal de Psicologia (CFP) 016/2000. Dessa forma, a pesquisa se iniciou com a aprovação do Comitê de Ética em Pesquisa da Universidade do Vale do Rio dos Sinos, RS, Brasil (CEP 12/005). Os participantes concordaram com a pesquisa mediante assinatura do Termo de Consentimento Livre e Esclarecido, no qual estavam claros os objetivos da pesquisa e as questões éticas inerentes a ela.

\section{Resultados e discussão}

\section{Transição e adaptação à parentalidade e à coparentalidade}

Esta categoria compreende os desafios relatados pelos participantes decorrentes da transição e da adaptação à parentalidade e à coparentalidade. Abarca também os conflitos coparentais e os descompassos referentes à organização do par parental, que tem seus reflexos na dinâmica familiar.

Os seguintes relatos mostram uma diferença expressiva nas falas de pais e de mães. A intensidade das dificuldades maternas vividas por elas, e a aparente tranquilidade e facilidade paterna, leva à conclusão de que isso se constitui como um fator estressor, apesar de os casais não admitirem, o que está implícito nas seguintes frases: “... eles querem meu sangue, às vezes eu tô à beira de um ataque, porque eles querem muito, o pai me ajuda, pega, leva, mas quando é aquela hora de todo mundo se ajeitar, tem que ser com a mãe" (mãe B); “... bem tranquilo, nunca ninguém disse eu tô cansado, eu não posso agora, ou tenho compromisso, a gente adia de tudo muitas vezes... às vezes eu trago trabalho pra casa..., mas daí a gente deixa pra fazer depois que eles tão dormindo...a gente nunca preteriu as crianças porque tem que fazer alguma tarefa assim, a gente para, larga tudo, e depois, quando sobrar um tempo, a gente faz..." (pai B).

Identifica-se, corroborando a literatura (Gabriel \& Dias, 2011), que a mãe continua sendo a principal responsável e quem acompanha a criança na maior parte do tempo. Mesmo que o pai esteja envolvido e participe dos cuidados com os filhos, este se refere ao tempo em que estão disponíveis, ou quando são solicitados: “... a criança fica mais apegada à mãe... quer brincar mais com a mamãe, daí o papai tenta, mas quer ficar com a mamãe, e aí a mamãe às vezes quer fazer alguma coisa minha, olha uma revista, lê um e-mail, fazer alguma coisa, e não consegue...e daí tu vê que o papai consegue mais fazer, mas não é porque ele tomou a iniciativa... nesse momento cria um certo estresse...tu pensa assim, 'bem hoje que hoje eu queria um tempinho só pra mim, sabe'...” (mãe A).

As frases a seguir evidenciam que, durante a transição e a adaptação à parentalidade, as mulheres sentem mais as dificuldades desse momento do que os homens. Pode-se pensar que, em função de as mães passarem quatro meses em licença-maternidade, e terem que retornar ao mercado de trabalho, conciliando suas atividades profissionais com as domésticas e parentais, elas relatam sentir uma sobrecarga física e emocional. Já os homens retornam ao trabalho logo em seguida ao nascimento do filho, talvez não sentindo de forma tão intensa como as mulheres essas mudanças: “... eu senti dificuldade no começo, quando ele se adaptou a mim e eu a ele... de repente já não almoçava mais, eu já não tomava banho, eu não cortava mais as unhas, sair pra cortar cabelo então nunca na vida..." (mãe D).

A partir do seguinte relato nota-se que os homens conseguem manter seus espaços pessoais; em contrapartida, as mulheres ficam mais envolvidas com as tarefas da casa e com os filhos. Talvez eles 
não se sintam tão sobrecarregados porque conseguem preservar seus espaços de lazer: "o que ajuda muito na nossa convivência é saber respeitar os gostos, a minha esposa tem uma qualidade, eu tenho 34 anos e jogo videogame até hoje e vou jogar com 64..." (pai D).

Cabe destacar que, nos genitores do casal C, não apareceram conflitos e dificuldades durante esse período de transição da conjugalidade para a parentalidade. Isso é evidenciado a partir das seguintes frases: “é normal, é pai e mãe pela primeira vez, nunca a gente sabe de tudo né, sempre tem uma coisa nova prá gente aprender..." (pai C); "bem normal, bem tranquilo, pede pra fazer... faz numa boa..." (mãe C).

Esses resultados sustentam a literatura (Mosmann, Wagner, \& Féres-Carneiro, 2006; Nichols \& Schwartz, 2007; Van Egeren \& Hawkins, 2004; Wagner, 2011), que aponta a necessidade de adaptações entre os genitores durante esse período de transição da conjugalidade para a parentalidade. De modo que, para alguns casais, pode ser mais difícil e, para outros, vivenciado com menos sofrimento, dependendo da adaptabilidade do casal.

\section{Coparentalidade}

Esta categoria contempla questões referentes à coparentalidade exercida pelo par parental. É composta por duas subcategorias que abarcam as vivências dos casais concernentes ao apoio mútuo e o compartilhamento de cuidados.

Apoio mútuo. Esta subcategoria compreende o auxílio entre os genitores no cuidado com os filhos. No geral, entre os casais entrevistados, parece haver uma reciprocidade de apoio, pois todos referiram a importância do diálogo nesse processo. Esse dado corrobora a literatura (Mosmann et al., 2006), que mostra que a comunicação é vista como facilitadora e essencial para adaptação dos papéis parentais às novas demandas: "... com bastante conversa... um apoia o outro no momento que não está legal..." (mãe A); “... eu sempre fui muito disposto assim, muito cooperativo... nunca me incomodei de fazer nada... pai tem que participar de tudo na criação... é uma ajuda mútua... tá com os filhos ali... é quase que automático... isso vai surgindo ao natural..." (pai B).

Esses dados mostram que os pais deste estudo demonstram um envolvimento e uma participação mais ampla com relação aos cuidados dos filhos. Não se restringem aos momentos de lazer e ao sustento financeiro, conforme apontado no estudo de Souza et al. (2007).

Apesar de existir esse apoio, o estresse inerente ao trabalho pode contribuir para que surjam conflitos. Deve-se considerar que, para os casais deste estudo, coincide a transição à parentalidade e à coparentalidade com o ingresso escolar dos filhos: “... daqui a pouco tu não está legal né, naquele dia... vai falar de forma um pouco mais ríspida, então tu está cansado, juntou uma função ou outra do trabalho... mas a gente sempre tenta chegar num consenso, as vezes lógico, tem atritos..." (pai A).

Entretanto, ainda que surjam conflitos, fica evidente novamente a importância da comunicação para conseguir administrar as dificuldades que são inerentes à rotina das famílias. Esse apoio mútuo aparece de forma menos intensa no casal D, o que fica evidente a partir da seguinte frase: “... não é exatamente igual, mas dá prá dizer que é uns sessenta a quarenta... todas as tarefas quase do $\mathrm{J}$. é ela que faz, mas às vezes ali, tem alguma coisa que eu sei fazer, eu não deixo ela terminar, às vezes eu me meto fazer, vou lavar louça, botar a roupa em molho, tirar alguma coisa, então eu diminuo aquele ritmo de tarefas dela assim...ou ela me pede, troca o J. e tal, eu troco, mas a maioria das tarefas é dela" (pai D).

Corroborando com o que sugere a literatura (Hernandez \& Hutz, 2009), percebe-se através dos relatos, que os genitores conseguiram assumir as novas tarefas a partir da chegada do bebê e mudaram suas atribuições a partir do término da licença-maternidade e a consequente inserção esco- 
lar dos filhos. Cabe ressaltar, que embora os casais não citem nas falas a questão da inserção escolar, esse foi o estímulo para a entrevista. As perguntas sobre a rotina dos cuidados foi referente à situação após término da licença-maternidade e retorno ao trabalho, e a inserção da criança na escola.

Nota-se que o ingresso na escola dos filhos demandou maior apoio entre os genitores para fazer frente ao processo. Durante esse período, não aparecem conflitos relacionados ao apoio propriamente dito, como na transição à parentalidade e à coparentalidade. As discordâncias surgem no desenvolvimento diário das funções coparentais, como apontam os estudos de Badinter (2011) e Bornholdt et al. (2007). O fato de os filhos permanecerem na escola em turno integral pode estar auxiliando os genitores no desempenho de uma coparentalidade mais funcional, uma vez que, durante todo o dia, a escola termina por assumir muitas das tarefas relacionadas à criança. Nesse contexto, identifica-se que existem bons níveis de acordo coparental entre os casais, pois eles definem de mútuo entendimento o que cada um vai fazer.

\section{Compartilhamento de cuidados com os filhos.}

Esta subcategoria abrange as questões da coparentalidade que se referem especificamente aos cuidados que ambos os genitores dispensam aos filhos. Destaca-se que os conteúdos referem-se também à forma como eles se organizam frente às novas demandas que são decorrentes desse processo.

Assim como no estudo de Wagner et al. (2005), nesses casais também se observa uma relativa divisão de papéis, na qual pais e mães compartilham tarefas referentes à educação e à organização do dia a dia dos filhos: “... de manhã eu dou a mamadeira, aí o A. acorda e vai fazer as coisas pra ele, vai se arrumar, aí ele pega e troca a fralda... enquanto eu levanto... ajudo ele trocar a roupa, eu escolho a roupa... mas, se acontecer, ele vai ter que trocar... enquanto o A. está colocando a roupinha, eu faço o lanchinho, arrumo a malinha dele e o pai leva para escolinha..." (mãe B). O pai complementa: “a única coisa é lavar as roupinhas dela só, quem faz é a F., porque o resto, banho... comida, principalmente no sábado se eu ficar com ela né...” (pai C).

A partir dos relatos dos casais B e C, pode-se observar que existe uma divisão igualitária com relação ao cuidado dos filhos. Porém, há os cônjuges em que a divisão depende da necessidade, como no casal D. De acordo com o exposto, percebe-se a coexistência de modelos, como apontado pela literatura (Fleck \& Wagner, 2003), não predominando somente um tipo de estrutura: "um pouco da convivência nossa reflete na forma como a gente cuida do nosso filho, porque tem essa divisão, não tão igual, mas é satisfatório pra nós, e faz com que, às vezes ela está cansada, eu fico com ele, às vezes é eu que não quero ficar com ele, ela fica..." (pai D).

A literatura (Bornholdt et al., 2007; Badinter, 2011) tem apontado que, ao mesmo tempo em que o pai deseja participar dos cuidados com os filhos e das atividades domésticas, e a mãe verbaliza esse desejo, muitas vezes, ela não permite a sua entrada nesse espaço. Nota-se que os casais C e D dessa pesquisa corroboram esses estudos, enquanto os casais A e B contrariam esses resultados (Bornholdt et al., 2007; Badinter, 2011), o que indica processo de mudanças nos atuais papéis, pois algumas mães, ao perceberem que estão mais envolvidas com os cuidados dos filhos do que os pais, fazem um movimento para facilitar a entrada deles. Esse fator vem a contribuir para um bom desenvolvimento da coparentalidade, o que se evidencia nas seguintes frases: “... as vezes eu vejo assim que... eu tô cuidando mais dela...daí eu peço prá ele trocar, pra ter mais contato com ela..." (mãe A); “eu e ele, os dois, a gente leva, busca, eu tento deixar ele também, a gente tenta dividir pra ele participar também da vida do A" (mãe B).

A divisão dos cuidados com os filhos é relatada como satisfatória para os genitores deste estudo. Entretanto cabe destacar que, enquanto para alguns casais já está definido o que cada um faz, para outros, depende da demanda, o que reforça a importância da flexibilidade de papéis e de funções, e da 
comunicação (Mosmann, Wagner, \& Féres-Carneiro, 2006; Nichols \& Schwartz, 2007; Van Egeren \& Hawkins, 2004; Wagner, 2011) para poderem trocar de tarefas de acordo com a necessidade.

Nesse contexto, de duplo trabalho e vida escolar precoce dos filhos, os pais foram impelidos a dividir com as mães os cuidados referentes às crianças. Nota-se que os pais deste estudo se mostraram envolvidos e participativos nas questões coparentais, o que pode estar demonstrando uma mudança na atualidade com relação aos papéis, uma vez que os genitores têm compartilhado essas tarefas, as quais antigamente eram vistas, exclusivamente, como de responsabilidade da mãe.

Divisão de tarefas domésticas. Esta categoria contempla os conteúdos referentes à forma como o par parental se organiza com a divisão de tarefas domésticas no contexto de duplo trabalho e vida escolar do filho. Destacam-se as percepções dos pais e das mães sobre suas atribuições domésticas e a forma de desempenhá-las.

Os resultados acompanham os estudos de Jablonski (2010) e Sutter e Bucher-Maluschke (2008) de que os homens demonstram dificuldades em compartilhar de forma igualitária as tarefas domésticas, pois estas ainda são vivenciadas com muito estranhamento pelos mesmos (Sutter \& Bucher-Maluschke, 2008). Os entrevistados dizem que dividem, mas se identifica nas falas que isso acontece quando é necessário e/ou quando lhe pedem: "quando precisa ele me ajuda... não chegamos assim a conversar...” (mãe C); “... se ela me pedir, numa boa sempre faço, mas se deixar pra mim aquilo parado pra eu fazer, pode esquecer" (pai D).

Algumas mulheres desta pesquisa ainda continuam assumindo mais tarefas de alta frequência e com horário fixo, como apontado no estudo de Vanalli e Barham (2012), enquanto outras dividem mais as tarefas com os cônjuges: "... eu levanto e é essa correria, arrumo ele, dou mamá, às vezes eu levo... se eu estou em casa, estou organizando a casa" (mãe B); "Como eu chego às sete e ele às cinco, dividimos, ele limpa a casa, eu lavo roupa, e dividimos as tarefas" (mãe C).

A divisão de tarefas domésticas também exige readaptação e flexibilidade por parte do casal, para que não seja mais um fator a contribuir e agravar os desafios vivenciados neste momento. A fala a seguir demonstra essa necessidade: "... tem um dia que tu está mais cansada, às vezes o F. lava mais louça, então ele brinca assim: 'a louça tá com saudades de ti'... daí eu brinco... 'tem um monte de roupa lá que está lá pra passar... que está lá pra lavar, e ninguém está reclamando'...” (mãe A).

Esses dados coincidem com os resultados encontrados pelos autores Vanalli e Barham (2012) e Souza et al. (2007), em que as mães relatam dedicar o dobro do tempo que os pais as atividades da casa e ao cuidado dos filhos, sentindo grande sobrecarga, enquanto que os pais se envolvem mais com o lazer e outras atividades nos finais de semana.

Também surgem as questões relacionadas aos papéis de gênero, em que predomina a concepção tradicional de família, onde a mulher é quem deve se dedicar aos cuidados do lar. Porém, com a diferença de que o homem não é o único provedor financeiro: "eu homem lavo a louça e assisto o esporte” (pai D); “... se tem a roupa pra lavar, claro, homem, geneticamente, acho que eles não enxergam o serviço..." (mãe D).

$\mathrm{O}$ fato de os pais estarem mais envolvidos e participativos no cuidado com os filhos não tem relação direta com uma maior apropriação também da vida doméstica, pois parece que alguns homens ainda seguem modelos tradicionais com relação aos serviços da casa. Em alguns momentos, os homens fazem uma distinção de quais são as tarefas das mulheres e quais são as dos homens (Sutter \& Bucher-Maluschke 2008).

Embora a transição para a parentalidade e a coparentalidade apresente suas dificuldades e alguns conflitos com relação ao cuidado com os filhos, parece estar havendo uma divisão mais igualitária e um maior acordo coparental entre os participantes do estudo. Entretanto, com relação às tarefas 
domésticas, existe uma divisão ainda não igualitária, mas que é relatada pelos participantes como satisfatória, o que reforça os estudos que mostram que essas tarefas ainda são mais delegadas e assumidas pelas mulheres, especialmente as de alta frequência e rotineiras.

\section{Considerações finais}

O objetivo do presente artigo foi analisar a transição para a parentalidade e a coparentalidade em casais cujos filhos ingressaram na escola de educação infantil logo após o término da licença-maternidade. Justifica-se sua relevância devido à escassez de estudos nacionais voltados à importância da coparentalidade para o desenvolvimento dos filhos e, também, devido ao enfoque majoritário dado pelas pesquisas à coparentalidade depois do divórcio. Considera-se que o ingresso escolar dos filhos tem sido adiantado, o que gera uma sobreposição de duas etapas do ciclo evolutivo familiar, pois os genitores, além de se adaptarem à parentalidade, precisam negociar seus papéis $\mathrm{e}$ suas funções coparentais.

Considerando as vivências relatadas pelos casais deste estudo, identifica-se um descompasso nas percepções de homens e mulheres. As mães deste estudo relataram que se sentiram mais sobrecarregadas com as novas tarefas e funções referentes ao período de transição para parentalidade, o que gerou algumas dificuldades para elas. Por outro lado, os pais não relataram compartilhar desta mesma sobrecarga. Talvez isso tenha ocorrido em função de os pais conseguirem manter seus espaços de lazer, e as mães se colocarem como responsáveis por dar conta de todas as demandas.

Já com relação ao compartilhamento de cuidados dos filhos, identifica-se que existe uma maior divisão mais igualitária entre os genitores. Os relatos indicam que a divisão ocorre de acordo com a necessidade, entretanto, pode-se questionar também se as mães deixam que os pais participem ativamente. Cabe destacar que, neste estudo, já se observa uma mudança nesse sentido, uma vez que algumas mães, ao se perceberem passando mais tempo com os filhos, delegam alguns cuidados aos pais. Parece que a inserção escolar precoce dos filhos, o duplo trabalho e a impossibilidade de assumir tudo as impele a fazer esse movimento.

Em contrapartida, nas tarefas domésticas, ainda existe menos divisão entre os casais desta pesquisa, pois algumas tarefas permanecem vinculadas ao papel de gênero. Nota-se que os homens têm-se empenhado no envolvimento e no desempenho dos papéis e das funções coparentais, permanecendo ainda com certo estranhamento e distanciamento das tarefas do lar.

Esses resultados, ainda que referentes a um número pequeno de participantes, parecem indicar algumas mudanças da atualidade, que têm seus reflexos na dinâmica familiar. Cabe ressaltar que, apesar das dificuldades e dos conflitos vivenciados durante esse período de transição à parentalidade e à coparentalidade, unidas às questões de duplo trabalho e da inserção escolar dos filhos, os genitores desta pesquisa apresentaram capacidade de adaptabilidade e bons níveis de acordo coparental.

Pode-se questionar se esses resultados referem-se à desejabilidade social, uma vez que a literatura sustenta este período do ciclo vital como de crise que tende a se refletir em uma diminuição nos níveis de funcionalidade. Nos casais entrevistados, não houve diferença entre o conteúdo das entrevistas conjugal e individual de cada cônjuge. Por outro lado, cabe ressaltar a dificuldade em conseguir casais que atendessem aos critérios de inclusão e demonstrassem interesse em participar desta pesquisa. Pode-se pensar que os que assentiram em participar não estejam com tanta dificuldade de fazer frente às demandas deste período.

Os resultados do presente estudo, desde uma abordagem qualitativa, permitiram uma aproximação à realidade destes casais, que apontou indícios de mudanças no desempenho da coparentalidade nesses pares parentais. Sugere-se que novas pesquisas sejam realizadas, contemplando um nú- 
mero maior de casais, desde uma perspectiva quantitativa, auxiliando no mapeamento das características da dinâmica conjugal e coparental nesta etapa de transição para parentalidade e coparentalidade, tão carente de estudos no contexto brasileiro.

\section{Referências}

Araújo, M. A. N., Gama, F. S., \& Silva, U. (2013). Creche de ontem e de hoje: o que os pais esperam desta instituição? Revista Psicologia, Diversidade e Saúde, 2(1), 3-20.

Badinter, E. (2011). O conflito: a mulher e a mãe. Rio de Janeiro: Record.

Bardin, L. (1977). Análise de conteúdo. Lisboa: Edições 70.

Beltrame, G. R., \& Bottoli, C. (2010). Retratos do envolvimento paterno na atualidade. Barbarói, (32), 205-226.

Bornholdt, E. A., Wagner, A., \& Staudt, A. C. P. (2007). A vivência da gravidez do primeiro filho à luz da perspectiva paterna. Psicologia Clínica, 19(1), 75-92.

Brasil. Ministério da Saúde. (2012). Conselho Nacional de Saúde. Resolução n ${ }^{\circ}$ 466, de 12 de dezembro de 2012. Regulamenta pesquisas envolvendo seres humanos. Brasília (DF).

Bustamante, V. \& Trad, L. A. B. (2005). Participação paterna no cuidado de crianças pequenas: um estudo etnográfico com famílias de camadas populares. Cadernos de Saúde Pública, 21(6), 1865-1874.

Conselho Federal de Psicologia. (2000). Resolução para pesquisa com seres humanos. Resolução 016/2000, Brasilia: CFP.

Cooper, C. L., \& Lewis, S. (2000). E agora, trabalho ou familia?: Pais e mães que trabalham fora aprendem como enfrentar as sobrecargas profissionais e familiares do dia-a-dia. São Paulo: Tâmisa.

Creswel, J. W. (2010). Projeto de pesquisa: métodos qualitativo, quantitativo e misto (3a ed.). Porto Alegre: Artmed.
Feinberg, M. E. (2003). The internal structure and ecological context of coparenting: A framework for research and intervention. Parenting: Science and Practice, 3(2), 95-131.

Feres-Carneiro, T. (1996). Família: diagnóstico e terapia. Rio de Janeiro: Vozes.

Fleck, A. \& Wagner, A. (2003). A mulher como a principal provedora do sustento econômico familiar. Psicologia em Estudo, 8(esp), 31-38.

Freitas, W. M. F., Silva, A. T. M. C., Coelho, E. A. C., Guedes, R. N., \& Costa, A. M. T. (2009). Paternidade: responsabilidade social do homem no papel de provedor. Revista de Saúde Pública, 43(1), 85-90.

Gabriel, M. R. \& Dias, A. C. G. (2011). Percepções sobre a paternidade: descrevendo a si mesmo e o próprio pai como pai. Estudos de Psicologia, 16(3), 253-261.

Gil, A. C. (1999). Métodos e técnicas de pesquisa social ( $5^{\mathrm{a}}$ ed.). São Paulo: Atlas.

Gomes, A. J. S., \& Resende, V. R. (2004). O pai presente: o desvelar da paternidade em uma família contemporânea. Psicologia: Teoria e Pesquisa, 20(2), 119-125.

Gravena, A. C. (2006). Retorno ao trabalho após o nascimento de um filho: percepções de professoras sobre sua experiência (Dissertação de Mestrado). UFSCar, São Carlos.

Grzybowski, L. S., \& Wagner, A. (2010). Casa do pai, casa da mãe: a coparentalidade após o divórcio. Psicologia: Teoria e Pesquisa, 26(1), 77-87.

Hernandez, J. A. E. \& Hutz, C. S. (2009). Transição para a parentalidade: ajustamento conjugal e emocional. Psico, 40(4), 414-421.

Jablonski, B. (2010). A divisão de tarefas domésticas entre homens e mulheres no cotidiano do casamento. Psicologia Ciência e Profissão, 30(2), 262-275.

Lamela, D., Costa, R. N., \& Figueiredo, B. (2010). Modelos teóricos das relações coparentais: revisão crítica. Psicologia em Estudo, 15(1), 205-216. 
McHale, J. P., Kuersten-Hogan, R., \& Rao, N. (2004). Growing points for coparenting theory and research. Journal of Adult Development, 11(3), 221-234.

Menezes, C. C., \& Lopes, R. C. S. (2007). Relação conjugal na transição para a parentalidade: gestação até dezoito meses do bebê. Psico-USF, 12(1), 83-93.

Mosmann, C., Wagner, A., \& Féres-Carneiro, T. (2006). Qualidade conjugal: mapeando conceitos. Paidéia, 16(35), 315-325.

Mosmann, C., Einsfeld, P., Silva, A. M., \& Terres-Trindade, M. (2012). Interação conjugal, coparental, parental e sintomas internalizantes e externalizantes dos filhos: resultados preliminares. Trabalho apresentado no Segundo Congresso de Iniciação Científica e Pós-Graduação (CICPG), São Leopoldo, RS.

Nichols, M. P., \& Schwartz, R. C. (2007). Terapia familiar: conceitos e métodos. Porto Alegre: Artmed.

Núcleo de Estudos e Pesquisas em Transtorno do Desenvolvimento. (2006). Entrevista sobre coparentalidade. Porto Alegre: UFRGS (material não publicado).

Pinheiro, L., Galiza, M., \& Fontoura, N. (2009). Novos arranjos familiares, velhas convenções sociais de gênero: a licença-parental como política pública para lidar com essas tensões. Estudos Feministas, 17(3), 851-859.

Ríos-González, J. A. R. (2005). ¿Los ciclos vitales de la familia y la pareja?: ¿crisis u oportunidades? Madrid: Editorial CCS.

Rizzo, G. (2010). Creche: organização, currículo, montagem e funcionamento ( $6 \mathrm{a}$ ed.). Rio de Janeiro: Bertrand Brasil.

Seabra, K. C. (2007). A paternidade em famílias urbanas: uma análise da participação do pai na creche-escola e nos cuidados com o filho (Tese de Doutorado). Universidade do Estado do Rio de Janeiro, Rio de Janeiro.

Seabra, K. C., \& Seidl-de-Moura, M. L. (2011). Cuidados paternos nos primeiros três anos de vida de seus filhos: um estudo longitudinal. Interação em Psicologia, 15(2), 135-147.

Sutter, C., \& Bucher-Maluschke, J. S. N. F. (2008). Pais que cuidam dos filhos: a vivência masculina na paternidade participativa. Psico, 39(1), 74-82.

Sluzki, C. (1996). La red social: fronteras de la práctica sistémica. Barcelona: Gedisa.

Souza, N. H. S., Wagner, A, Branco, B. M., \& Reichert, C. B. (2007). Famílias com casais de dupla carreira e filhos em idade escolar: estudos de casos. Aletheia, 26, 109-121.

Staudt, A. C. P., \& Wagner, A. (2008). Paternidade em tempos de mudança. Psicologia: Teoria e Prática, 10(1), 174-185.

Van Egeren, L. A., \& Hawkins, D. P. (2004). Coming to terms with coparenting: Implications of definition and measurement. Journal of Adult Development, 11(3), 165-181.

Vanalli, A. C. G., \& Barham, E. J. (2012). Após a licença maternidade: a percepção de professoras sobre a divisão das demandas familiares. Psicologia \& Sociedade, 24(1), 130-138.

Wagner, A., Predebon, J., Mosmann, C., \& Verza, F. (2005). Compartilhar tarefas?: papéis e funções de pai e mãe na família contemporânea. Psicologia: Teoria e Pesquisa, 21(2), 181-186.

Wagner, A. (Org.). (2011). Desafios psicossociais da familia contemporânea: pesquisas e reflexões. Porto Alegre: Artmed.

Yin, R. K. (1993). Applications of case study research. Philadelphia: Sage.

\section{Data de recepção: 01 de fevereiro de 2015 Data de aceitação: 17 de junho de 2015}

